\title{
Entrevista
}

\section{ENTREVISTA COM ANA LONGONI}

\section{Entrevista realizada em 4 de abril de 2019'1, por Paola Zamariola}

Investigadora, membro da Red Conceptualismos del Sur e atual diretora do departamento de atividades públicas do museu Reina Sofía.

Doutora em Artes pela Universidade de Buenos Aires, é especialista nos cruzamentos entre arte e política na Argentina e América Latina. Entre suas publicações se destacam: Roberto Jacoby. El deseo nace del derrumbe (2011), Leandro Katz (2013) y Vanguardia y revolución (2014).

\section{Paola Lopes Zamariola}

Doutoranda do Programa de Pós-Graduação em Artes Cênicas da Escola de Comunicações e Artes - ECA/USP. Investiga a cena latino-americana contemporânea, com ênfase para projetos que envolvem práticas artísticas e pedagógicas. Artista criadora do [pH2]: estado de teatro desde 2007, onde desenvolveu trabalhos como atriz, diretora e diretora de arte. Entre os anos de 2016 e 2019 fez parte do corpo editorial da Revista Aspas.

1. Transcrição de áudio da entrevista: André Felipe Costa Silva. 
ANA LONGONI - Bem, vou contar um pouco sobre como comecei a pesquisar. Comecei no início dos anos 1990, quando ainda era estudante de literatura na Universidade de Buenos Aires. Eu estava muito interessada em pesquisar as vanguardas e minha primeira orientadora foi a chilena Ana Pizarro, com quem comecei a trabalhar na história das vanguardas em alguns livros. Mas ela voltou para o Chile após o fim da ditadura e fiquei órfã na orientação da pesquisa; eu estava começando a pesquisar. Sempre me interessei muito pelos anos 1960 e queria muito trabalhar na intersecção entre arte e política. Quando eu era estudante de literatura, ouvi Maria Teresa Gramuglio falar sobre "Tucumán arde" em uma aula sobre a literatura argentina do século $X X$, e ela mencionou a experiência da qual fizera parte. Ela era a esposa de Juan Pablo Renzi e foi ela quem escreveu o manifesto de "Tucumán arde". Bom, eu ouvi sobre essa experiência pela primeira vez, que era uma espécie de mito sobre o qual não havia nada escrito, não havia documentos, não havia arquivo, não havia memória. Decidi então começar a investigar sobre "Tucumán arde", especialmente o processo de radicalização artística e política da vanguarda argentina dos anos 1960. E então, em uma das minhas primeiras entrevistas, conheci Mariano Mestman, um pesquisador da minha idade, que também estava começando a pesquisar sobre cinema e teatro nos anos 1960 em sua intersecção com a política, sobre a experiência do teatro de Norman Briski, a experiência do Cine Liberación etc. Então decidimos começar a trabalhar juntos e essa colaboração foi muito importante. Eu sempre entendi a pesquisa como um trabalho necessariamente coletivo e sempre achei muito importante formar uma equipe, pensar em conjunto, compartilhar o que se encontra. Um pouco na contramão da lógica institucional, já que o mundo acadêmico tende a ser muito competitivo, muito solipsista e muito isolado e onde cada um se sente dono de seu próprio tema, seu enredo. Bem, então eu sempre tentei contribuir a partir de outra lógica, contra essa tendência. Então com Mariano e com o meu orientador na época, Enrico Teisa, formamos um grupo de pesquisa que foi o primeiro desse tipo em 1993/1994, chamado de "Arte, Cultura e Política nos anos 60". Nós pegamos um primeiro livro, fizemos um primeiro arquivo. E é daí que vem o nosso livro sobre "Tucumán Arde", que foi o primeiro livro sobre minha pesquisa com Mariano, publicado em 2000. E a partir desse momento 
passei a me dedicar, sempre que pude, a pesquisas sempre colaborativas, sempre com outras pessoas. Em 2007, criamos a Rede Conceptualismos del Sur, que também é um grande marco, digamos, na ideia de estabelecer plataformas colaborativas coletivas, projetos comuns, compartilhamento de posicionamentos, pesquisa de arquivos, publicações e exposições, feitas em colaboração e em articulação com outras pessoas.

\section{REVISTA ASPAS - Acho que podíamos falar um pouco sobre o contexto em que surgiu a Rede Conceptualismos del Sur.}

ANA - Curiosamente, nós a fundamos em Barcelona. Foi fundada por dois argentinos e dois peruanos junto com outros pesquisadores (também havia as brasileiras Cristina Freire e Rosário Carnaval). Bem, nós nos reunimos em uma reunião realizada no Museu de Arte Contemporânea de Barcelona, nos anos de Manolo Borja [Manuel Borja-Villel]. Foi um projeto chamado "Vivid [Radical] Memory" que tratava das ligações entre a América Latina e a Europa Oriental no nível das práticas conceituais. Eles me convidaram e, através de mim, Miguel López, Emilio Tarazona do Peru, Fernando Davis da Argentina e outras pessoas foram convidadas. E, claro, nós, latino-americanos, muitas vezes acabamos nos encontrando e nos conhecendo em reuniões de agenda e em perguntas das instituições do centro. $E$ aí entendemos que era uma tarefa desmedida, gigante e difícil fundar uma rede latino-americana a partir da América Latina, indo além da institucionalidade, ou seja, sem pensar que necessariamente tinha que partir de universidades ou museus, mas que era o desejo de um grupo de pessoas, ativando outras formas e gerando outras lógicas de troca e compartilhamento. $E$ a verdade é que era muito bonito porque no começo éramos quatro, mas em um ano já éramos quinze e em dois anos estávamos com cinquenta pessoas e era muito impressionante como esse desejo, essa vontade de construir um coletivo em outros termos se espalhou, e se espalhou rapidamente, consolidando-se em uma estrutura totalmente nova. $E$ acho que teve muito a ver com um momento muito diferente do atual; onze, doze anos se passaram. Tínhamos plena consciência de que estávamos em um momento em que o mercado de arte e as grandes instituições do mundo da arte começaram a ter um interesse muito ávido por esse tipo de prática e por seus restos materiais. $\mathrm{E}$ foi um momento importante para lutar pelo que essas práticas significavam para nós. Para que esses significados 
não se esvaziassem, não se des-historializassem, que esses arquivos não se dispersassem, não se reificassem. Então, essa era a batalha que nos cabia.

ASPAS - Então, pensando um pouco sobre sua carreira, quais são os principais momentos que poderiam ser marcados quando os temas relacionados à arte política se intensificaram? E de que maneira isso foi mudando com o tempo? Quais significados e processos foram ou estão ligados?

ANA - Bem, eu estava contando sobre essa cena inicial dos anos 1990, que Mariano e eu éramos muito jovens e começamos a pesquisar. Em geral nos deparamos com muita resistência; eu diria que a década de 1990 é um momento em que a questão sobre a relação entre arte e política era uma questão fora da agenda, uma questão que não interessava. Até mesmo pessoas muito próximas a viam como fora de contexto. Era uma questão demodé, que já havia passado, que não era interessante. Isto é, nem no mundo curatorial, nem no mundo acadêmico, foi uma questão pertinente. Mas Mariano e eu insistimos porque estávamos interessados nessa questão, nessa intersecção, nesse cruzamento problemático e, acima de tudo, porque estávamos pensando em uma época em que essa questão era crucial. Eu diria que isso muda no final dos anos 1990, em 1999, com a exposição "Global Conceptualism", que foi feita no Queens Museum, em Nova York, e a partir de 2000, com muito mais clareza. Em 2001, na Argentina, uma mudança radical se inicia de alguma forma e o tem arte e política começa a ser uma questão recorrente e quase uma moda. Isso é muito forte também, não é? $E$ tem a ver, por um lado, com esse interesse insipiente institucional e mercadológico por essas práticas. Mas também tem sua contrapartida, pois é um momento de crescente ativismo e o ativismo precisa encontrar cenas, genealogias que o precedam e o alimentem e que o conectem. E então, a pergunta sobre a história anterior também começou. A partir daí ocorreu um fenômeno muito estranho: a cena dos anos 1960 se tornou uma espécie de cena mítica, fundadora das práticas dos anos 2000. É muito forte. Como se nada tivesse acontecido nesse meio tempo. Isso também foi muito forte, porque parecia que tudo derivava de "Tucumán arde" e da cena da vanguarda radicalizada. No caso do Brasil, Helio Oiticica e Lygia Clark. E que no meio havia um grande marasmo, um vazio. Então, me parece que havia essa percepção de que estava 
se cometendo um engano, porque foi construída uma história que bloqueou a possibilidade de pensar em continuidades de práticas que, embora marginais e minoritárias, existiam naqueles duros anos da ditadura e assim por diante. Foi essa pergunta que respondemos com "Perder la forma humana", um projeto da Rede que iniciamos em 2010, já que Manolo Borja, que já estava aqui no Museu Reina Sofía, nos convidou para produzir uma amostra sobre Conceptualismos del Sur. E me pareceu que os anos 1960 já haviam sido excessivamente revistos e decidimos ir contra e pesquisar os anos 1980. Porque nos pareceu que entre o mito dos 1960 e o mito do 2000 - 2001 na Argentina, 1994 com o Zapatismo - havia um território pouco explorado para considerar e descobrir uma série de práticas que necessitavam ser visíveis e conectadas entre si. Então foi nesse momento que decidimos trazer à tona os anos 1980, um pouco sem saber o que iríamos encontrar. Tínhamos a sensação de que nos anos 1980 aconteceram muitas coisas no nível de redes de colaboração e solidariedade internacional, de movimentos de direitos humanos com práticas criativas (como El Siluetazo ou No+), de territórios underground e de práticas contraculturais. Mas não sabíamos muito bem que materialidade iríamos encontrar para dar uma forma expositiva a esse processo em dois anos. Foi arriscado começar a investigar. $\mathrm{E}$, de fato, noventa por cento do que foi mostrado em "Perder la forma humana" nunca havia entrado em um museu, eram práticas totalmente exumadas.

\section{ASPAS - E quais foram as estratégias desse trabalho colaborativo com pessoas (pesquisadores, artistas) de contextos tão diversos? Como foi possível acessar esses arquivos? Você pode nos contar um pouco sobre o trabalho a esse respeito?}

ANA - Bem, eu posso dizer várias coisas. Por um lado, o projeto também foi um projeto muito ambicioso, no sentido do número de pessoas que participaram. Nós éramos 31 pesquisadores e acabamos formando um grupo coordenador de sete pessoas. Em outras palavras, foi um projeto difícil de gerenciar no nível do número de pessoas envolvidas. E, além disso, espalhados em diferentes lugares da América Latina. Desde que começamos, deixamos muito claro que não poderíamos explicar tudo, que seria um processo de pesquisa mais sobre alguns episódios, alguns tópicos, algumas conexões. $E$ no começo partimos desses quatro territórios que eu mencionei antes, as redes - 
os territórios underground, movimentos de direitos humanos, práticas criativas e dissidências sexuais. Quatro áreas que pensamos ter acontecido muito em relação às novas formas de articulação da arte e da política nos anos 1980. E logo depois percebemos que esse formato fechado não funcionava, porque nos impedia de tornar visível o que nos interessava, que eram as conexões. Então, mudamos radicalmente a maneira como estávamos pensando e trabalhando. Começamos a trabalhar em mapas ou cartografias conceituais e ver que os conceitos geralmente emanavam de nossas próprias práticas, dos próprios protagonistas (ativistas ou artistas) que propunham categorias ou inventavam palavras para explicar o que estavam fazendo, que era novo; um vocabulário, um novo glossário. Com essas palavras, poderíamos não apenas falar sobre essas práticas, mas sobre outras. Então poderíamos compartilhar relações que talvez não fossem óbvias, eram relações secretas, microrrelações, no sentido de contatos interpessoais. Por exemplo, a viagem de [Nestor] Perlongher de Buenos Aires a São Paulo e o que essa viagem representou no sentido da sua escrita, mas também na ida e vinda de livros, conexões, contatos, conceitos... Lá ele conhece Guattari, Suely [Rolnik]. O que ele traz para Buenos Aires contamina. Então começamos a pensar em termos de contágios, contaminações, genealogias: modos de relação. Obviamente, nem tudo se conectava a tudo. Mas nós estávamos muito interessados em pensar que o que aconteceu, por exemplo, no movimento de direitos humanos não foi totalmente dissociado do que estava acontecendo nos territórios under, que poderia haver uma conexão lá. Até as mesmas pessoas poderiam estar atuando em todos esses lugares. Como o exemplo claro de [Fernando] Coco Bedoya serigrafiando com as mães da Plaza de Mayo durante o dia, de noite produzindo os Museus Bailables nas discotecas de Buenos Aires. Era a mesma pessoa. E isso é muito bom, reconhecer que os modos são múltiplos e cruzam as mesmas biografias.

\section{ASPAS - E onde estavam esses materiais, por exemplo, daqueles clubes} ou dos grupos mais underground? Quem trouxe esses materiais?

ANA - É por isso que eu disse a você que noventa por cento desse material nunca foi mostrado. E não estava em lugar nenhum, não estava em nenhum arquivo. Ou seja, a pesquisa não foi iniciada a partir de um arquivo pré-existente, mas a própria pesquisa produziu arquivo. Bem, esses materiais eram mantidos por pessoas que nos levavam de uma a outra, que os mantinham 
mais por uma questão afetiva, pois eram suas memórias da juventude ou suas principais experiências de vida. Mas nenhum desses materiais estava em instituições ou em arquivos, digamos, formais. Foi debaixo da cama, em cima do armário, no álbum da família. Um pedaço de papel nos levou para outro. De alguns episódios chave não havia nada, não havia um único documento. Então tivemos que inventar estratégias para mostrá-los sem documentos. O caso de Cucaño, por exemplo. A ação chave deste grupo de Rosario foi uma ação de perturbação de uma missa, na igreja mais importante de Rosario, frequentada por toda a cúpula militar durante a ditadura. E o que eles fizeram foi incorporar diferentes personagens que alteraram totalmente a cerimônia da missa. Uma pessoa ficava ao fundo da sala de confissão e gritava textos de Maldoror ou outros textos do conde de Lautrémont sobre masturbação. Outra chorava com uma boneca nos braços dizendo que era seu filho morto. Outro subiu atrás do padre que conduzia a missa e espiava sob a tanga de Cristo. $E$ todas aquelas situações que pareciam não ter nada a ver uma com a outra, desequilibraram a missa. Dois deles foram presos, mas os outros se misturaram entre os fiéis e escaparam. Eles conseguiram parar a missa naquele momento. E dessa ação que todos ouviram falar em Rosário não há um único documento, porque não havia espectadores, não havia vontade de se registrar. O que lhes interessava era produzir essa perturbação radical, esse deslocamento, que mudaria da normalidade vigente para um lugar de estranhamento. Então o que fizemos foi contatar Guillermo Giampietro, que é um dos membros do Cucaño e que agora mora em Trieste, e que foi para lá participar das ações de desmanicomialização. E pedimos a ele que fizesse um relato em vídeo de como foi essa experiência. Foi uma experiência de como contar uma história sem documentos.

\section{ASPAS - O que resta quando não há registro? Nenhum texto, nenhuma foto, nada.}

ANA - Bem, não havia sequer um arquivo aqui. $O$ arquivo tinha que ser feito e por anos as práticas eram clandestinas, eram marginais, eram secretas, eram estratégias contra a censura, boca a boca, não eram públicas, não eram institucionais, recusavam-se a se institucionalizar. $E$ além disso foram anos onde o registro não importou em absoluto. Hoje ninguém faz nada sem filmar ou gravar. Neste momento era interessante fazer, então não havia vontade de 
se registrar. Dessa forma, é claro, os documentos eram muito pobres, eram muito pequenos, eram muito poucos ou não havia nada.

ASPAS - Ou significavam risco de vida. É como as coisas que são encontradas na casa em seu texto "Embutes de la memoria". Muitas coisas devem ter sido reviradas durante essas investigações, certo? Bem, trazendo mais para o contexto atual. Se você pudesse mencionar algumas práticas de artistas e pesquisadores que continuam a inspirá-la em relação ao tema da arte e política, arquivo etc. Se você pudesse selecionar alguns procedimentos, algumas tensões deles, quais contribuições seriam essas e por que você acha que elas são importantes para nossa atualidade?

ANA - Bem, posso contar um pouco sobre a política de arquivos que estamos tentando promover a partir da Rede Conceptualismos del Sur. Nós começamos a partir desse diagnóstico contraditório. Porque por um lado muitos desses recursos documentais não tinham status de arquivos, seus depositantes ou seus proprietários não tinham nenhuma consciência de que tinham um material valioso; eram mantidos por uma questão afetiva, amorosa, mas não davam a eles um status de arquivo. E é a própria pesquisa que os torna visíveis, dá a eles um valor. Mas isso também produz, nesse contexto de febre arquivística contemporânea, um crescente interesse por parte do mercado de arte. $\mathrm{E}$ muitas vezes o mercado gera uma distorção muito grande entre obra e documento, como se pudessem se dividir, "bem, essas fotos são a obra e essas fotos fazem parte do arquivo, porque não são tão bonitas". Em seguida, gera uma divisão muito problemática, porque não há obras no sentido clássico, mas em todo caso há documentos ou registros ou suportes que têm a ver com um processo de ação, e que não são a obra. O trabalho é irrepetível, é efêmero, é desmaterializado nesse tipo de prática. Muitas vezes são práticas que se recusam a ser chamadas de arte. Querem ser uma ação política ou ficam no limite do que são. Então esse fenômeno começou a ocorrer. E em um contexto como a América Latina, onde há tão poucas políticas públicas de arquivos, onde os acervos de memória são tão abandonados, a Rede, em associação com outras instituições públicas como universidades ou museus, tentou começar a produzir intervenções ou influenciar as condições para que esses documentos pudessem ser valorizados, salvaguardados, não dispersos e garantidos para serem preservados. Mas também garantir que 
eles fossem socializados, que eles pudessem estar disponíveis para consulta pública. Portanto, temos basicamente quatro pontos, um é manter a unidade dessas coleções, impedi-las de se dispersar e que sejam vendidas em partes, para tentar mantê-las em seus locais de origem, no lugar onde essas práticas ocorreram. Porque muitas vezes as instituições do Norte garantem as melhores condições de conservação, mas também extrapolam, isto é, tiram esses documentos e dificultam o acesso dos pesquisadores latino-americanos, e também os descontextualiza. Então queremos que eles fiquem no lugar deles o máximo possível. E por outro lado, acessibilidade, socialização desses materiais e preservação. Esses seriam os quatro pontos do que chamamos de acordo ético na política de arquivos. Bem, e com essa política de arquivos, trabalhamos em muitos arquivos específicos, como o arquivo de Clemente Padín em Montevidéu; o arquivo de memórias da resistência em Santiago do Chile, que trata das práticas gráficas durante a ditadura militar de Pinochet; o arquivo de Graciela Carnevale em Rosário, que trata do processo de 1968 da vanguarda e de "Tucumán arde"; o arquivo de Juan Carlos Romero em Buenos Aires, e muitos outros arquivos com os quais estamos trabalhando no Paraguai, Uruguai, Argentina, Brasil, Peru e outros países.

\section{ASPAS - Parece que a importância deste trabalho ético é também fazer obras visíveis que não se encaixam na história oficial da arte, que estão fora do cânone. Para que essa multiplicidade seja garantida.}

ANA - Sim, aí eu coloco outra questão. Como eu disse antes, esses dilemas, que incluem até mesmo a própria investigação, além das perguntas críticas que são feitas, muitas vezes chamam a atenção ou trazem visibilidade para o mercado. Também há a contradição de que muitas vezes a instituição é tão hábil em expandir suas fronteiras que se chamamos atenção para práticas preliminares ou práticas de fronteira, ou práticas que negam sua condição artística, muitas vezes volta-se para o mundo da arte. Um exemplo pode ser o Siluetazo, que foi aquela prática ligada ao movimento de direitos humanos na Argentina em 1983 para dar uma forma gráfica, uma forma de representação visual aos desaparecidos. E foi a iniciativa de três artistas, mas eles propuseram para as Mães da Plaza de Mayo e foi uma multidão de pessoas, de manifestantes, que colocaram seus corpos para fazer o Siluetazo. Nessa condição, digamos, de uma iniciativa artística, guiada por um movimento social e que é assumida pelo 
corpo de uma multidão, para se arriscar e dar corpo ao ausente neste ritual coletivo, é o que forma o caráter do Siluetazo. Mas eles nunca falaram de arte, falaram sobre uma ação visual e sobre fazer com que a mídia de massa ecoasse a denúncia. Era o que importava para eles, não entrar na história da arte. E por muitos anos se esqueceu completamente a origem artística da iniciativa, ninguém estava interessado em quem tinha sido o autor, não era relevante. Eu acho que foi em 2007 ou 2008 que fizemos o livro sobre Siluetazo, um livro coletivo que saiu na Argentina, e rapidamente começou a ter um interesse por parte das instituições em colecionar o Siluetazo, o que era uma contradição total. O que pode ser colecionado de um evento político? Algumas fotos, registros, depoimentos... E isso também gerou, creio eu, uma estranha distorção, porque havia um material que começou a ser vendido no mundo da arte e que começou a se repetir como uma imagem estereotipada do Siluetazo, também trazendo esse tema. Há o vetor institucional e o vetor do mercado, vetores que, a essa altura, são impossíveis de se esquivar, mas que produzem efeitos em relação a como podemos recuperar essas experiências. E eles nos colocam o tempo todo diante de dilemas sobre os efeitos de uma pesquisa crítica.

ASPAS - E se pudéssemos então pensar nas contradições e tensões que temos nas questões ligadas à arte e à política e também no poder que os arquivos institucionalizados podem ter. Qual poderia ser um olhar possível para não deixarmos de questionar isso? Considerando que este pode ser um lugar de apropriação do mercado da arte sobre um assunto. Como então continuar trabalhando a partir dessas perspectivas? Quais seriam as negociações que parecem importantes para você e que não são esquecidas? ANA - Bem, a primeira coisa para mim é entender que o mundo da arte e seus cruzamentos com a política não são territórios pacíficos nem estáveis. É mais como um campo de batalha e um campo de luta de significados e contradições como você disse, certo? Então, para mim, o importante é o confronto de ideias, de práticas, gerando outros códigos éticos com relação a isso, não dando por perdido, mas tentando gerar institucionalidades de outra natureza que possam preservar esses materiais. Digamos, eu sei que o mercado e a instituição do museu são, sem dúvida, máquinas muito poderosas e onipresentes, mas acho que podemos escapar de sua lógica e até gerar fissuras internas; desvios, confrontos, antagonismos, desativações. 
ASPAS - E a partir de sua experiência como curadora dos lugares por onde passou, que experiências específicas você poderia compartilhar? Em um lugar onde o desejo de trabalhar com essas questões é coerente com todos os problemas que elas envolvem.

ANA - Sim, nunca me defini como curadora. Eu sempre penso que sou uma pesquisadora que às vezes faz exposições, às vezes faz livros, às vezes tem que fazer programação, como aqui. Os recursos são diversos. Mas a curadoria também me parece que é a possibilidade de desafiar outros públicos, que não seriam alcançados de outra maneira. $E$ isso também permite outros tipos de implantações, diferentes daquelas da publicação. Outras conexões, outras experiências físicas, outras escalas de experiência. Bem, obviamente, há momentos cruciais nessa experiência como curadora que são "Perder la forma humana" ou a mostra sobre Oscar Masotta que foi chamada de "La teoría como acción", que fiz nos últimos anos e terminou este ano. Porque, é claro, são temas ou processos de pesquisa que me levaram a novas e inesperadas conexões e ativações com o presente. Pensando que as ressonâncias que existem sobre modos de configuração do presente poderiam ter esses passados e seus ecos, suas capacidades de ativação. As memórias adormecidas que de repente poderiam desencadear conexões inesperadas. E experiências inquietantes, desconcertantes e perturbadoras. Ou seja, eu nunca penso em curadoria como uma narrativa fechada ou como um território estável, mas como algo que se não faz com que a gente mude ao longo do processo, não está funcionando bem. Deveria produzir outros tipos de experiências. $E$ também produzir a possibilidade de novas pesquisas. Sempre penso em curadorias como convites para continuar conectando, como mapas abertos, como produção de uma caixa de ferramentas para completar, implantar e ativar em outros contextos. E de outras formas.

ASPAS - Me chama a atenção em sua trajetória, em sua pesquisa, o lugar que o corpo está tomando. As práticas investigadas, além de politizadas, também poderiam estar ligadas à alegria ou movimento underground. Tenho curiosidade em saber como o trabalho com o corpo foi apresentado em suas pesquisas. Se você acha que há algo lá, em "Perder la forma humana”" ANA - Sim, eu acredito que em "Perder la forma humana" o corpo definitivamente irrompeu como território. Território onde se manifestou a violência, mas também onde se manifestaram experiências de liberdade. Na verdade, 
antes de chegarmos ao nome "Perder la forma humana", o nome do projeto era "Poner el cuerpo". Ou seja, o tema do corpo, corpos desobedientes, corpos dissidentes, estava presente o tempo todo em nossas deliberações. Ficou muito claro que esse período que estávamos investigando, desde as ditaduras até o novo ciclo inaugurado pelo Zapatismo e pelo Hijos [Hijos e Hijas por la Identidad y la Justicia contra el Olvido y el Silencio] e outras práticas dos anos 1990. Ali o corpo apareceu como apoio e como o território onde tanto a repressão como a possibilidade de metamorfose, de transformação, de mudança, de deliberação foram experimentadas. Como também como um território de batalha. Há um texto muito bom que Roberto Amigo escreveu para o catálogo de Perder la forma humana chamado "Hacer política con nada", e que tem a ver justamente com isso. Ou seja, dissolvidas as formas de organização do período anterior - a forma partido, a forma guerrilha -, derrotadas tais experiências emancipatórias, era preciso inventar a ação política do zero, ou seja, da falta de coletividade, da pobreza de recursos, da nudez, do corpo. E isso nos pareceu uma espécie de denominador comum para muitas das práticas que estávamos pensando. Por isso a predominância do tema do corpo.

\section{ASPAS - Você poderia comentar um pouco sobre o próximo projeto que está desenvolvendo aqui no Museu Reina Sofía, sobre o eixo que este museu ocupa hoje?}

ANA - Bem, por um lado nós também estamos há dois anos trabalhando em um novo projeto coletivo na Rede chamado "El giro gráfico", que será uma exposição daqui a alguns anos aqui no museu. Isso vai entrar em cena na América Latina e tem a ver com trazer o presente para o museu. Parece que temos um novo ciclo histórico atravessado por urgências e que também nos interpelam no sentido de repensar as formas de ação política diante de um novo contexto, um contexto muito hostil, um contexto que tende a ser chamado de neofascismo ou fascismo contemporâneo. Ou seja, é um ciclo histórico, como já dissemos, muito precipitado, muito rápido, nas maneiras de instalar o terror, a devastação, a aniquilação. E que achamos que é muito importante usar o museu como uma caixa de ressonância que conecta e amplifica e evidencia as formas que estão gerando múltiplas resistências. Resistência a partir do feminismo, dos movimentos indígenas, movimentos LGBTs, movimentos estudantis. Diferentes resistências em todo o continente 
e além dele estão ocorrendo. Também no nível da defesa da dimensão ecológica, contra o extrativismo e a devastação do planeta. Bem, são questões urgentes e, ao mesmo tempo, são questões de longa data e são questões que encontramos múltiplas formas que chamamos de "gráficas". Não são necessariamente gráficas, às vezes são formas de visibilidade através de bordados ou ação de rua ou performance. Diferentes formas de entender o criativo como ferramenta de denúncia, mas também de transformação política e imaginação de novos caminhos do futuro. Então, para nós este projeto é totalmente imperioso, urgente, necessário e é uma maneira de nos opor à tristeza, à desolação e ao isolamento que este novo ciclo histórico está produzindo nos corpos. Então, por um lado, estamos trabalhando duro nesse projeto, já somos 25 pesquisadores trabalhando lá. $E$ é um projeto muito emocionante e também muito complexo. Porque, além disso, como um museu permite que o presente entre? O presente muda o tempo todo, como você disse. O presente é o impeachment da Dilma ou é Bolsonaro? O presente é tudo isso. Mas como mostramos isso? E o que vai acontecer daqui a dois anos? É tão vertiginoso. Então é um desafio. Como não congelar o presente? Como deixá-lo entrar em um museu como esse? Então também é um projeto com muito debate interno. E, por outro lado, há um ano estou aqui dirigindo a parte de atividades públicas e isso também é um desafio. Eu, no começo, quando concordei em vir aqui, falei sobre "sudaquear" o museu. E o que significa "sudaquear" o museu? Latino-americanizar o museu. E pensei naqueles contágios, contaminações, nesses buracos, essas formas de diferentes lógicas que também podemos instalar a partir de outras práticas, outros modos de sucessão, outros modos de colaboração, que não são os da instituição pública espanhola, centrados, legitimados, como é esta. Mas ao mesmo tempo pode acontecer aqui perturbando uma certa ordem, mas também enfatizando certas formas, certo? Gerando outras lógicas dentro da instituição. Para mim, a instituição não é unívoca nem unilateral, mas é também um território onde lógicas diversas e disputadas podem ser enfrentadas. Então, estamos trabalhando com uma série de linhas-força que imagino como vetores transversais que vão, de alguma forma, dar uma série de novas narrativas ou contranarrativas que o museu está instalando. Mas sem essas linhas de força, elas podem parecer tentativas isoladas ou focos 
desconectados entre si. Então estamos trabalhando com algumas linhas de força que têm a ver com repensar o Museu, com pensar novas formas de institucionalidade, mas também pensar as contradições que o Museu como uma instituição de grande porte tem, por exemplo, entre um discurso muito progressista ou denuncista em alguns aspectos, mas que reproduz certas lógicas de precarização. Ou um museu que se diz feminista mas que reproduz certas lógicas patriarcais em seu interior. Bem, essas contradições. Colocá-las em evidência, enfatizá-las e trabalhá-las. Não resolvê-las. Porque não se trata de resolvê-las, mas sim de evidenciá-las e pensar em como elas podem ser abordadas. Outra das linhas de força tem a ver com ação radical e imaginação; feminismo, ativismo, movimento LGBT, ambientalismo. Outra tem a ver com desconforto contemporâneo, pensar nas emergências de novas formas de violência, a gravidade da crise ecológica, a medicalização das patologias contemporâneas, toda essa questão. E outras têm mais a ver com como o passado ou as histórias sobre o passado afetam o presente. Por exemplo, a exposição inaugurada na sala de Richard Serra, que aborda políticas e estética da memória, das transições entre ditadura e pós-ditadura, não só na América Latina, mas também na Europa, na Espanha, na África. De que maneira podemos pensar em comum esses processos que muitas vezes bloqueiam a lembrança de episódios traumáticos, como diz Suely [Rolnik]? Memórias que não são processadas e que estão bloqueando a possibilidade de uma sociedade processar essas experiências traumáticas e, ao mesmo tempo, gerando uma amnésia muito patológica. Então este é um dos vetores. O outro tem a ver com as interseções entre vanguarda e política, pensar momentos históricos dessa articulação entre práticas artísticas que se pretendem vetores que incidam sobre o social, sejam transformadores e ajudem-nos a pensar, como espécie de laboratórios, novas formas de habitar o mundo, também são muito importantes para se recuperar. Penso nas vanguardas russas, mas também, por exemplo, na exposição que existe agora de Amauta, as vanguardas latino-americanas etc. $E$ também penso em tudo o que tem a ver com o pensamento descolonial latino-americano e como esse pensamento pode nos ajudar, a partir do Sul, como um exercício de pensamento situado também a pensar em outras cenas. Por exemplo, a crise migratória europeia. 